\title{
Radiossensibilidade de esporos de Paenibacillus larvae subsp. larvae em mel
}

\section{Sensitivity radiation of spores of Paenibacillus larvae subsp. larvae in honey}

\author{
Wanderley Mendes de Almeida, ${ }^{*}$ Hélio Vital, ${ }^{* *}$ Dulce Maria Tochetto Schuch, ${ }^{*}$ Raul Ribeiro de Carvalho, ${ }^{* * *}$ \\ Zander Barreto Miranda*
}

\begin{abstract}
Resumo
Esta pesquisa investigou a eficácia da radiação para inviabilizar os esporos da bactéria Paenibacillus larvae subsp. larvae, agente causal da "cria pútrida americana" ou "loque americana", enfermidade exótica no Brasil, que provoca um alto índice de mortalidade em abelhas e que inviabiliza a comercialização do mel. É uma doença altamente contagiosa, que acarreta grandes prejuízos econômicos aos produtores, podendo inclusive provocar embargos na exportação do produto. Foram usadas amostras de $60 \mathrm{~g}$ de mel contaminadas com esporos de $P$. larvae na concentração de $3,5 \times 10^{3}$ esporos $/ \mathrm{mL}$. Após 0 processo de radiação gama com doses de $0 ; 5 ; 7,5 ; 10 ; 12,5$ e $15 \mathrm{kG}$, em esquema de duplicata, as amostras foram submetidas a análises bacteriológicas para determinação da fração de esporos inviabilizada por cada tratamento. A aplicação de 5,0kGy reduziu em $97,0 \pm 1,2 \%$ e $98,3 \pm 0,5 \%$ o número de esporos viáveis, sendo a maior redução correspondente ao mel menos viscoso, ao passo que doses superiores reduziram as concentrações abaixo do limar de deteç̧ão (5,5 esporos $/ \mathrm{mL})$.
\end{abstract}

Palavras-chave: Paenibacillus larvae, mel, esporos, irradiação, cria pútrida americana.

\begin{abstract}
Keywords: Paenibacillus larvae, honey, spores, irradiation, foulbrood.

\section{Introdução}

O mel de abelhas é um produto suscetível à contaminação por diversos microrganismos, incluindo esporos de bactérias e mofos. Uma das mais importantes doenças que atacam as abelhas produtoras de mel no estágio larvar é a "cria pútrida americana", enfermidade produzida pelo microrganismo Paenibacillus larvae, especialmente perigosa, pela longevidade infectante do esporo, que acarreta graves prejuízos econômicos e que pode dizimar a criação. Um fator preocupante é a introdução da doença no território brasileiro, através da importação de mel contaminado.
\end{abstract}

This research has investigated the efficacy of gamma radiation in inactivating spores of Paenibacillus larvae subsp. larvae that causes the "American foulbrood disease", a highly contagious disease still exotic in Brazil that kills bees and contaminates honey, preventing its commercialization. Samples of $60 \mathrm{~g}$ of two types of honey contaminated with $3,5 \times 10^{3} \mathrm{spores} / \mathrm{mL}$ concentrations of that microorganism were gamma irradiated to doses of $0,5,7.5,10,12.5$ and $15 \mathrm{kGy}$ and then counted for spores of $P$. larvae. The analyses indicated reductions of $97,0 \pm 1,2 \%$ and $98,3 \pm 0,5 \%$ in the number of active spores for a $5 \mathrm{kGy}$ dose, the higher figure corresponding to the honey with lower consistency. Doses equal to $7.5 \mathrm{kGy}$ or higher yielded no active spores 9 the detection threshold was 5.5 spores $/ \mathrm{mL}$ ). Finally, the corresponding values for $\mathrm{D}_{10}$ (approximately $3 \mathrm{kGy}$ ) and the fractions of inactivated spores for the two types of honey were determined as functions of the radiation dose.

\section{Material e métodos}

Os experimentos realizados consistiram das seguintes etapas, listadas em ordem cronológica: 1) preparação das suspensões de esporos de Paenibacillus larvae subsp larvae; 2) fortificação das amostras de mel com P. larvae; 3 ) irradiação e 4) análise bacteriológica das amostras. Com exceção da terceira etapa, a qual foi realizada no Laboratório de Irradiação da Seção Nuclear da Divisão de Defesa Química, Biológica e Nuclear do CTEx, as demais foram realizadas no LANAGRO/ RS, para exame e detecção do $P$. larvae. As quatro etapas citadas foram aplicadas a dois tipos de mel, que apresen-

\footnotetext{
* Ministério da Agricultura, Pecuária e Abastecimento.

** Centro de Tecnologia do Exército.

${ }^{\star * *}$ Departamento de Tecnologia dos Alimentos da Faculdade de Veterinária da Universidade Federal Fluminense. Rua Vital Brazil Filho, 64 . Niterói, RJ - CEP 24230-340.

Autor para correspondência: Zander Barreto Miranda. E-mail: zander@vm.uff.br.
} 
tavam viscosidades diferentes e consistiam da mistura de vários méis brasileiros. Os experimentos foram realizados, em duas fases, realizadas em épocas diferentes, cada uma delas empregando uma das duas diferentes misturas de mel, sendo que os resultados da primeira fase permitiram uma redução do intervalo das doses aplicadas nas amostras irradiadas na segunda fase. A segunda etapa dos experimentos incluiu a inoculação das amostras empregadas de mel com as suspensões de esporos de $P$. larvae, cuja preparação foi descrita no item anterior. Duas suspensões padronizadas com esporos de $P$. larvae foram preparadas, uma para cada fase dos experimentos, sendo que ambas apresentavam a mesma concentração inicial de esporos viáveis $\left(3,5 \times 10^{3}\right.$ esporos/mL de mel).

$\mathrm{Na}$ primeira fase dos experimentos, usou-se uma amostra de mel de $600 \mathrm{~mL}$, resultante da mistura de vários méis brasileiros (previamente analisados e negativos para a presença de esporos de $P$. larvae), a qual havia sido inoculada com $1 \mathrm{~mL}$ de uma suspensão padronizada de esporos de $P$. larvae com 2,1 x106 esporos/mL. A amostra com $600 \mathrm{~mL}$ de mel inoculado, preparada pelo LANAGRO/RS, foi enviada para o Rio de Janeiro em 10/05/05 (primeira fase) para fins de fracionamento e, em seguida, irradiação no CTEx-RJ. No LANAGRO/RJ essa amostra inicial foi subdividida em 10 amostras contendo 60 gramas de mel cada, acondicionado em frascos plásticos cilíndricos $(4 \mathrm{~cm}$ de diâmetro e $7 \mathrm{~cm}$ de altura), com tampas fechadas e seladas. As novas amostras foram submetidas a cinco diferentes doses de radiação (5; 7,5; 10; 12,5 e 15kGY) gama, em esquema de duplicata.

Os procedimentos descritos anteriormente foram também seguidos na segunda fase dos experimentos, sendo que o fracionamento, produziu 12 amostras com 37 gramas de mel fortificado cada, a partir de uma única amostra com $450 \mathrm{~mL}$ (também resultante de uma mistura de vários outros tipos de méis brasileiros, estéreis para $P$. larvae), à qual havia sido adicionado $1 \mathrm{~mL}$ de uma suspensão padronizada com 1,6 x $10^{6}$ esporos $/ \mathrm{mL}$.

Duas etapas de irradiação foram realizadas, uma para cada conjunto de amostras, sendo que a primeira delas viabilizou um ajuste fino do intervalo das doses a serem aplicadas. $O$ quadro 1 lista as principais informações relativas às duas etapas de irradiação.

\begin{tabular}{|l|c|c|}
\hline \multirow{2}{*}{\multicolumn{1}{|c|}{ Parâmetro }} & \multicolumn{2}{c|}{ Especificação } \\
\cline { 2 - 3 } & $1^{{ }^{a}}$ Etapa & $2^{\underline{a}}$ Etapa \\
\hline Período $(2005)$ & $19-22$ de maio & 28 e 29 de novembro \\
\hline Número de Amostras & 10 & 12 \\
\hline Doses Aplicadas $(\mathrm{kGy})( \pm 8 \%)$ & $0 ; 5 ; 20 ; 35$ e 50 & $0 ; 5 ; 7,5 ; 10 ; 12,5$ e 15 \\
\hline Taxa de Dose Média $(\mathrm{kGy} / \mathrm{h})( \pm 8 \%)$ & 1,70 & 1,67 \\
\hline Temperatura Média na Irradiação $\left({ }^{\circ} \mathrm{C}\right)$ & 28 & 33 \\
\hline
\end{tabular}

Quadro 1: Parâmetros relevantes associados à irradiação das amostras

Para cálculo dos tempos de exposição das amostras, foi usado um programa previamente desenvolvido para tal, que leva em consideração, além do decaimento da fonte de césio137, a densidade e as dimensões das amostras (Vital, 2000a,b). Como exemplo, para uma amostra irradiada com
10kGy em 19 de maio de 2005, foi determinado um tempo de exposição total de $5 \mathrm{~h} 53,5 \mathrm{~m}$, correspondente a uma taxa de dose igual a $28,27 \mathrm{~Gy} / \mathrm{min}$. O mesmo programa informou que a atividade da fonte havia sido reduzida em $11,5 \%$ desde sua calibração em outubro de 2000; que, em média, a amostra (preenchida com mel até $5 \mathrm{~cm}$ de altura) absorveu dose $5 \%$ menor do que o faria se fosse plana, devido à presença do gradiente vertical da taxa de dose $(3,3 \% / \mathrm{cm})$; e que $2,5 \%$ da dose foi atenuada pela própria amostra antes de ser efetivamente absorvida pelo restante dela. Descontados estes três fatores, determinou-se uma correção total de -17,8\% em relação à taxa de dose medida na época da calibração (Vital, 2005).

\section{Resultados e discussão}

Nas análises bacteriológicas realizadas nas amostras testemunho e irradiadas, foram identificadas as colônias de esporos de $P$. larvae viáveis ainda presentes. A porcentagem de redução do número de esporos viáveis foi então determinada comparando-se o número de colônias observadas na alíquota de cada amostra irradiada, inoculada no meio sólido seletivo, com o número de colônias obtidas com uma alíquota de idêntico volume das amostras testemunho, inoculadas em placas que continham o mesmo meio sólido seletivo. Os dados são estimados, pois o método aplicado não se destina à contagem direta de esporos, mas sim de uma análise comparativa do número de colônias. $\mathrm{O}$ Quadro 2 resume os parâmetros mais relevantes associados às análises para determinação do porcentual de redução do número de esporos viáveis de $P$. larvae proporcionado pela exposição das amostras à radiação gama. Compara os resultados obtidos para as amostras irradiadas com 5kGy com aqueles relativos às amostras não irradiadas $(T)$. $O$ volume analisado em cada amostra foi de $20 \mathrm{~mL}$.

Para fins de ilustração, informa-se que a dose de 5kGy foi aplicada nas duas etapas (1 e 2) dos experimentos, realizadas em maio e novembro (respectivamente), em esquema de duplicata. Neste mesmo quadro observa-se que o tratamento por irradiação gama com dose de 5kGy reduziu o número de esporos viáveis nas amostras pesquisadas em 97,0 $\pm 1,3 \%$ e em $98,3 \pm 0,5 \%$, respectivamente na primeira etapa e na segunda etapa dos experimentos. A fração sobrevivente, listada na quarta coluna, indica, para cada etapa 1, a média do número de colônias de esporos de $P$. larvae viáveis após a irradiação com dose de 5kGy (numerador $\mathrm{M}_{\mathrm{i}}$ ) sobre a média do número de colônias de esporos de $P$. larvae viáveis nas amostras não irradiadas (denominador $\mathrm{T}_{\mathrm{j}}$ ). Os erros associados às reduções percentuais médias supracitadas foram calculados usando-se propagação dos desvios-padrão associados aos números

de colônias.

Para as demais doses aplicadas: 7,5; 10; 12,5; 15; 20; 35 e 50 , a redução porcentual do número de colônias viáveis foi de $100 \%$, pois não foi observada nenhuma colônia de $P$. larvae sobrevivente. 


\begin{tabular}{|c|c|c|c|c|}
\hline Dose (kGy) & Amostra & $\begin{array}{c}\text { Número de } \\
\text { Colônias Viáveis }\end{array}$ & $\begin{array}{c}\text { Fração } \\
\text { Sobrevivente }\end{array}$ & $\begin{array}{c}\text { Redução } \\
(\%)\end{array}$ \\
\hline \multirow{4}{*}{0} & 1 & 146 & - & - \\
\cline { 2 - 5 } & 2 & 182 & - & - \\
\cline { 2 - 5 } & Média $\left(\mathrm{T}_{1}\right)$ & $164 \pm 25$ & $164 / 164$ & 0 \\
\cline { 2 - 5 } & 3 & 83 & - & - \\
\cline { 2 - 5 } & 4 & 71 & - & - \\
\cline { 2 - 5 } & Média $\left(\mathrm{T}_{2}\right)$ & $77 \pm 8$ & $77 / 77$ & - \\
\hline \multirow{4}{*}{5} & 1 & 7 & - & - \\
\cline { 2 - 6 } & 2 & 3 & $5 / 164$ & $97,0 \pm 1,3$ \\
\cline { 2 - 6 } & Média $\left(\mathrm{M}_{1}\right)$ & $5 \pm 3$ & - & - \\
\cline { 2 - 6 } & 3 & 1 & - & - \\
\cline { 2 - 6 } & 4 & 1 & $1 / 77$ & $98,7 \pm 0,5$ \\
\cline { 2 - 5 } & Média $\left(\mathrm{M}_{2}\right)$ & 1 & & \\
\hline
\end{tabular}

Quadro 2: Redução porcentual do número de esporos viáveis de $P$. larvae em mel para diferentes doses de radiação gama

No processo de inativação dos esporos do $P$. larvae pela radiação gama, os valores obtidos demonstraram que a dose de 5 kGy inativou $98,7 \%$ dos esporos da bactéria $P$. larvae existente em $20 \mathrm{~mL}$ da amostra de mel fortificada $(3500$ esporos de P. larvae $\mathrm{mL}$ de mel) e eliminou $100 \%$ da microbiota acompanhante normalmente existente no mel. Analisando $20 \mathrm{~mL}$ dessa mesma amostra fortificada nas doses de $7,5,10,12,5$ e 15, houve redução de $100 \%$ dos esporos do $P$. larvae em comparação ao grupo controle, ressalta-se, porém, que o método de análise utilizado tem a sensibilidade de detectar menos de 10 esporos por $\mathrm{mL}$ de mel.

As pesquisas bacteriológicas realizadas, não se limitaram apenas à busca de esporos de $P$. larvae. A presença de vários outros microrganismos, comumente encontrados nos meios de cultura utilizados também foi investigada, incluindo esporos de outras espécies de bactérias, para determinação da eficiência da irradiação na descontaminação desses meios. A microbiota acompanhante se refere aos microrganismos que naturalmente estavam presentes nas amostras de mel, usadas como matriz de fortificação incluindo diversas espécies de microrganismos esporulados como os dos gêneros Bacillus, Brevibacillus, Paenibacillus, além de bolores e leveduras. Os resultados indicam que a microbiota acompanhante foi totalmente eliminada pelo processo de irradiação em todas as doses, incluindo 5kGy, comprovando que a irradiação foi bastante eficiente na eliminação dos demais esporos que normalmente estão presentes no mel. Esse fato facilitou muito a detecção de $P$. larvae, pois este apareceu isolado nas amostras irradiadas com 5kGy. Todos os interferentes como o Paenibacillus alvei que aparecia nas amostras testemunho, e não foi detectado, sugerindo que esporos de $P$. larvae são mais resistentes à irradiação no mel do que a maioria dos esporos da microbiota acompanhante.

O método de análise conhecido por "Método da curva de sobrevivência" oferece a vantagem de prever concentrações de bactérias tão reduzidas pela irradiação, que seria inviável detectá-las usando o método de contagem em placas. A relação entre dose e fração sobrevivente é exponencial, sendo a curva da dose em função do logaritmo da fração sobrevivente uma linha reta. $O$ método faz uso do valor $D_{10}$, um parâmetro que serve como um indicador da sensibilidade da bactéria à radiação e que permite estimar a dose necessária para se tratar um alimento, objetivando-se eliminá-la desse meio. Sendo $\mathrm{N}_{0}$ o número de bactérias inicialmente presentes, $\mathrm{N}$ o número após a aplicação de uma dose $D$ de radiação, será dado pela equação 1(URBAIN, 1986):

$$
\log _{10}\left(\mathrm{~N} / \mathrm{N}_{\mathrm{o}}\right)=-\mathrm{D} / \mathrm{D}_{10} \text { Eq. (1) }
$$

$\mathrm{O}$ valor $\mathrm{D}_{10}$ corresponde, portanto, à dose necessária para reduzir a população em um ciclo logaritmo, ou seja, a um décimo da população inicial $\left(\mathrm{N}_{\mathrm{o}}\right)$ ou inativar $90 \%$ da população original. Da mesma forma, uma dose de $2 \mathrm{D}_{10}$ dará $1 \%$ de sobreviventes e uma de $3 D_{10}$ poupará apenas $0,1 \%$ da população. Ressalta-se, porém, que na prática, tal aproximação é um tanto conservadora, pois desconsidera o aumento dos efeitos indiretos produzidos pela radiação com o aumento da dose, ou seja, a intensificação da ação letal dos radicais livres sobre os microrganismos (ibid.). A Figura 1 representa, em escala logarítmica, a redução percentual do número de colônias viáveis de $P$. larvae observada nas duas etapas dos experimentos. As curvas de sobrevivência tracejadas correspondem às funções lineares ajustadas aos dois pontos experimentais de cada etapa ( 0 e $5 \mathrm{kGy}$ ), na forma $y=\log N / N_{0}=-a D$, cujo coeficiente "a" correspondente à declividade da curva obtida pela análise estatística, é fornecido no Quadro 3 para cada etapa, além de seu valor médio e respectivo erro.

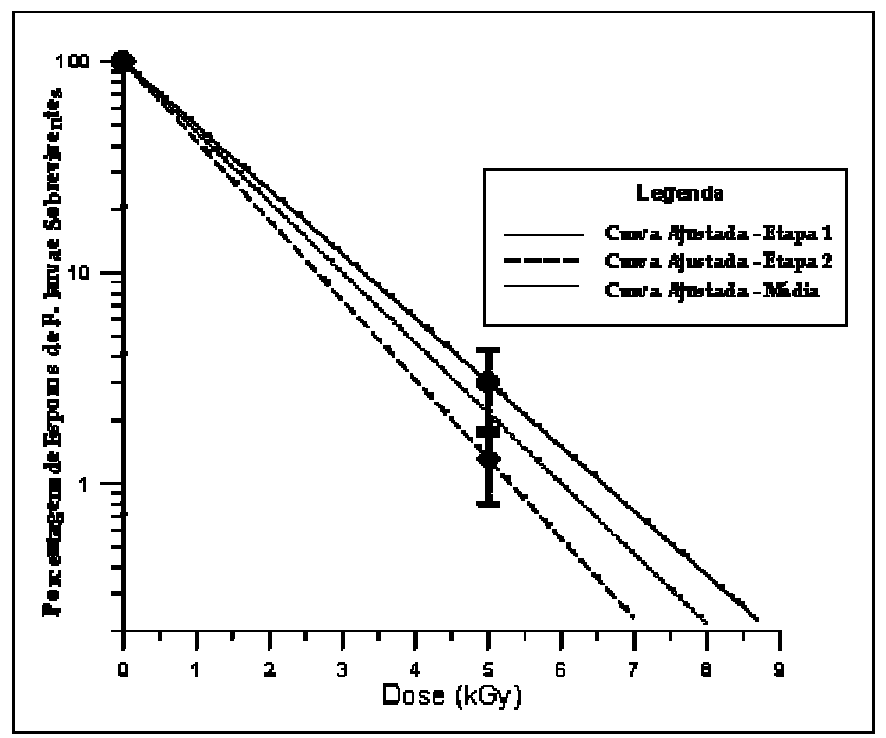

Figura 1: Percentagem de esporos de P.larvae sobreviventes em função da dose

\begin{tabular}{|c|c|}
\hline Etapa & a \\
\hline 1 & $-0,305$ \\
\hline 2 & $-0,377$ \\
\hline Média & $-0,341 \pm 0,036$ \\
\hline
\end{tabular}

Quadro 3: Coeficientes angulares das curvas de sobrevivência de esporos de $P$. larvae. 
O ajuste médio (curva tracejada intermediária na Figura 3), obtido segundo o Método da curva de sobrevivência e usandose as frações observadas de esporos viáveis de $P$. larvae irradiados, informa que uma dose de 8kGy, por exemplo, causaria inativação de $99,8 \%$ da população de esporos.

Da Equação 1 conclui-se que o coeficiente angular "a", cujos valores determinados experimentalmente estão listados no Quadro 3, está relacionado com o valor de $D_{10}$ da seguinte maneira: $a=-1 / D_{0}$. O Quadro 4 lista os valores de $D_{10}$ determinados a partir desta relação e relativos à primeira e segunda etapa dos experimentos, além do valor médio correspondente às duas etapas.

\begin{tabular}{|c|c|}
\hline Etapa & Valor de $\mathrm{D}_{10}(\mathrm{kGy})$ \\
\hline 1 & 3,3 \\
\hline 2 & 2,7 \\
\hline Média & $3,0 \pm 0,3$ \\
\hline
\end{tabular}

Quadro 4: Valores de $D_{10}$ para inativação de esporos de $P$. larvae obtidos experimentalmente

De posse de $D_{10}$, pode-se calcular as concentrações de esporos viáveis de $P$. larvae sobreviventes a doses superiores a $5 \mathrm{kGy}$. O Quadro 5 informa as porcentagens e concentrações sobreviventes de esporos de $P$. larvae (usando-se o valor médio de $D_{10}$ e a concentração inicial de esporos usada nos experimentos, igual a $3,5 \times 10^{3}$ ), calculadas com o uso Equação 1.

\begin{tabular}{|c|c|c|c|}
\hline Dose (D) (kGy) & $\mathrm{D} / \mathrm{D}_{10}$ & $\mathrm{~N} / \mathrm{N}_{\circ}$ & $\mathrm{N}^{\circ}$ Esporos $/ \mathrm{mL}$ \\
\hline 0 & 0 & 1 & $3,5 \times 10^{3}$ \\
\hline 3,0 & 1,00 & $10^{-1}$ & $3,5 \times 10^{2}$ \\
\hline 5,0 & 1,67 & $2,2 \times 10^{-2}$ & $7,5 \times 10^{1}$ \\
\hline 6,0 & 2,00 & $10^{-2}$ & $3,5 \times 10^{1}$ \\
\hline 7,5 & 2,50 & $3,2 \times 10^{-3}$ & $1,1 \times 10^{1}$ \\
\hline
\end{tabular}

Quadro 5: Parâmetros referentes à inviabilização de esporos de $P$. larvae em função da dose, calculados pelo Método da curva de sobrevivência com $D_{10}=3,0$ kGy

Os experimentos forneceram um dado adicional que pode ser usado para refinar a curva de sobrevivência de esporos de $P$. larvae em função da dose. Trata-se da inviabilização de todas as suas colônias pela aplicação de 7,5 kGy na segunda etapa. O uso do valor de $D_{10}$ determinado para essa etapa indica que nesta dose, restariam apenas 5,8 esporos $/ \mathrm{mL}$, concentração muito próxima ao limiar mínimo de detecção da técnica usada $(5,5$ esporos $/ \mathrm{mL})$ e portanto, com boa probabilidade de não ser detectável, o que explicaria o resultado encontrado. Contudo, o mesmo não pode ser dito sobre a concentração prevista usando-se o valor médio de $\mathrm{D}_{10}$ obtido nas duas etapas, o qual prevê 11 esporos $/ \mathrm{mL}$ para $7,5 \mathrm{kGy}$, a qual deveria ter sido detectada. Esse fato indica que a concentração foi superestimada e que na verdade deveria estar abaixo de 5,5 esporos $/ \mathrm{mL}$, que é o limite de detecção. Adotando-se, portanto, esta concentração limite, tem-se o terceiro ponto na curva de sobrevivência: 5,5 esporos $/ \mathrm{mL}$ de mel para a dose de 7,5kGy. Dessa forma, pode-se então ajustar um polinômio do segundo grau aos três pontos, como um refinamento ao ajuste linear anteriormente usado para descrever a curva de sobrevivência. Fazendo-se $\ln \left(\mathrm{N} / \mathrm{N}_{\mathrm{o}}\right)=\mathrm{y}$, busca-se uma função na forma $y=a \cdot D^{2}+b . D+c$ que melhor se ajusta ao conjunto de pontos experimentais.

A Equação 2: $\log _{10}\left(N / N_{0}\right)=-0,01645 D^{2}-0,2513 D$, descreve a curva de sobrevivência encontrada, a qual define uma parábola. $O$ Quadro 6 inclui previsões sobre a redução da população $(\mathrm{N})$ de esporos de $P$. larvae irradiados em mel. A última coluna baseia-se na concentração inicial de esporos usada nos experimentos.

\begin{tabular}{|c|c|c|}
\hline Dose (D) (kGy) & $\mathrm{N} / \mathrm{N}_{\circ}$ & $\mathrm{N}^{\circ}$ Esporos $/ \mathrm{mL}$ \\
\hline 0 & 1 & $3,5 \times 10^{3}$ \\
\hline 5,0 & $2,2 \times 10^{-2}$ & $7,5 \times 10^{1}$ \\
\hline 7,5 & $1,6 \times 10^{-3}$ & $5,5 \times 10^{0}$ \\
\hline 10 & $7,0 \times 10^{-5}$ & $2,4 \times 10^{-1}$ \\
\hline 15 & $3,4 \times 10^{-8}$ & $1,2 \times 10^{-4}$ \\
\hline 20 & $2,5 \times 10^{-12}$ & $8,7 \times 10^{-9}$ \\
\hline 25 & $2,7 \times 10^{-1 /}$ & $9,6 \times 10^{-14}$ \\
\hline
\end{tabular}

Quadro 6: Parâmetros referentes à curva de inviabilização de esporos de $P$. larvae em função da dose descrita por um ajuste quadrático

A Figura 2 mostra o ajuste quadrático, que descreve a curva de sobrevivência de esporos de P. larvae irradiados.

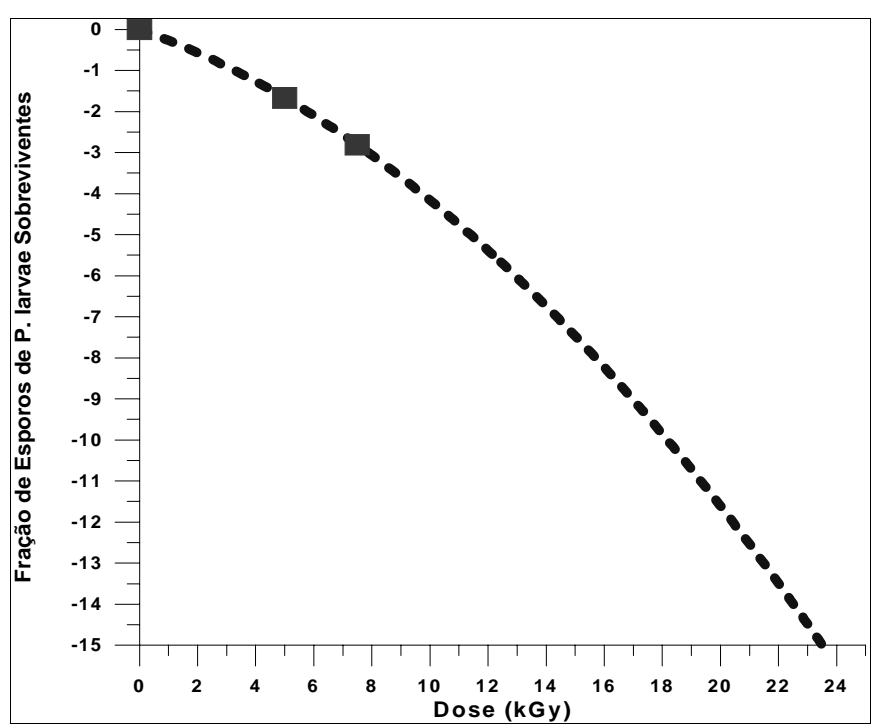

Figura 2: Curva de sobrevivência de esporos de $P$. larvae em mel ajustada a uma função quadrática.

Uma consulta ao Quadro 6 e à Figura 2 permite o cálculo do número de esporos viáveis de $P$. larvae em amostras de mel após irradiação com uma dose conhecida. Ressalta-se, contudo que, aos valores listados, estão associadas incertezas que podem se tornar significativamente elevadas em doses muito superiores àquelas usadas nos experimentos, tendo em vista que constituem resultados obtidos por extrapolação.

Nos trabalhos consultados, foram encontrados dois valores de doses normalmente usadas para esterilização de materiais e instrumentos apícolas suspeitos de contaminação: 10kGy e 25kGy. Observando-se os dados do Quadro 6 e Figura 2, conclui-se que o tratamento com 10kGy acarreta uma redução 
de aproximadamente 4 ciclos logarítmicos apenas, portanto, insuficiente para garantir a esterilização de objetos e amostras com resíduos de mel que apresentem concentrações iniciais elevadas de esporos, como por exemplo, $10^{6}$ esporos $/ \mathrm{mL}$. Por outro lado, amostras tratadas com 25kGy podem ser consideradas totalmente isentas de esporos viáveis de $P$. larvae, pois tal dose é suficiente para reduzir a população de esporos em 17 ciclos logarítmicos. A dose ótima para esterilização dependerá da concentração inicial de esporos contaminantes presentes nas amostras, visto que o ideal é que ocorra a inativação de todos os esporos, visto que se desconhece a concentração mínima de esporos de $P$. larvae necessária para dar início a um novo surto da doença nos apiários.

Sabe-se que durante a irradiação, são produzidos radicais livres, formados principalmente pela ação da radiação ionizante sobre as moléculas de água do meio. Esses produtos altamente reativos, em sua maioria, rapidamente se recombinam e desaparecem, contudo também se difundem pelo meio, atacando preferencialmente o DNA cromossômico ou a membrana das bactérias, o que acaba por eliminá-las. Os danos produzidos diretamente pela radiação somam-se a esses efeitos indiretos produzidos pelos radicais livres, sendo que eles predominam em alimentos com alto teor de água, como é o caso do mel.

Verificou-se que o mel fortificado usado nas amostras da primeira etapa dos experimentos (realizada em maio) apresentava-se mais denso, viscoso e dotado de menor fluidez quando comparado ao mel usado na segunda etapa (realizada em novembro). Tal informação é importante porque poderia explicar a diferença entre os valores de $D_{10}$ (embora não muito significativa em termos estatísticos) encontrados nas duas etapas: 3,3kGy e 2,7kGy, respectivamente. Nesse caso, os radicais livres formados nas amostras da segunda etapa dos experimentos, teriam maior mobilidade, em virtude da maior fluidez do mel, e, portanto, atingiria mais intensamente a carga microbiana presente, do que nas amostras da primeira etapa dos experimentos, nas quais o mel apresentava-se mais denso, oferecendo maior resistência ao movimento dos radicais livres. A mesma dose (5kGy) teria causado uma maior redução da carga microbiana nas amostras da segunda etapa do que naquela da primeira, como foi observado nos experimentos. Uma outra clara indicação da importância relativa dos efeitos indiretos nas amostras é a diferença, crescente com a dose, que pode ser observada entre as previsões obtidas a partir do ajuste linear à curva de sobrevivência, comparadas com aquelas baseadas no ajuste quadrático. Nota-se que as doses previstas pelo

\section{Referências}

BRASIL. Ministério da Agricultura, Pecuária e Abastecimento. Métodos Analíticos Oficiais para Análises Microbiológicas para Controle de Produtos de Origem Animal e Água - Instrução Normativa № 62, de 26 de Agosto de 2003, publicado no DOU de 18.09.2003,seção 1, p.14, Brasília, DF, 2003.

URBAIN, W.M. Food Irradiation, USA: Academic Press, Inc. 351p., 1986. segundo ajuste para se atingir o mesmo grau de redução da população de esporos viáveis de $P$. larvae são menores que aquelas baseadas no primeiro ajuste.

$\mathrm{Na}$ literatura, podem ser encontrados vários exemplos de curvas de sobrevivência que também se mostram muito semelhantes a segmentos de parábolas com concavidades voltadas para baixo, como é o caso da inativação de esporos de Clostridium botulinum por irradiação, os quais também são muito resistentes (Urbain,1986).

Observou-se também que a carga microbiana interferente inicial, encontrada nas amostras pesquisadas em maio, foi muitas vezes maior e mais diversificada que naquelas pesquisadas em novembro. Considerando-se ainda que, nas amostras de maio, a redução da população de esporos viáveis de $P$. larvae (97\%) foi menor que nas amostras de novembro $(98,3 \%)$, pode-se aventar a hipótese de que a maior competição com outras espécies poderia ter estimulado os mecanismos de defesa e de reparos a danos (membrana, DNA) dos esporos do P. larvae, excitando-os e mantendo-os mais ativos e eficientes durante a irradiação, de tal forma que os esporos da primeira etapa teriam se mostrado consideravelmente mais resistentes à radiação do que aqueles presentes na segunda etapa dos experimentos.

\section{Conclusões}

Considerando-se apenas os efeitos microbiológicos, o processo de irradiação mostrou-se uma opção muito eficiente para a eliminação, no mel, de esporos de $P$. larvae. A aplicação de 7,5kGy, considerada uma dose intermediária, reduziu a concentração de esporos viáveis de $P$. larvae (igual a $3,5 \times 10^{3}$ esporos/mL antes da irradiação) e da microbiota acompanhante (esporos de $P$. alvei, dentre outras espécies) para abaixo do limite de detecção (5,5 esporos $/ \mathrm{mL}$ ).

O uso do Método da curva de sobrevivência, o qual assume uma relação linear entre o logaritmo da fração da população sobrevivente pós-irradiação e a dose, forneceu o valor $D_{10}=3,0 \pm 0,3 k$ Gy para a inativação de esporos de $P$. larvae em mel. Um refinamento da curva de sobrevivência, usando-se um ajuste quadrático em substituição ao linear, permitiu a extrapolação mais precisa da fração sobrevivente para doses mais elevadas e indicou que a dose de 10kGy é insuficiente para garantir a descontaminação de instrumentos e materiais apícolas com resíduos de mel sujeito à contaminação por esporos de $P$. larvae, ao passo que o uso da dose de 25kGy mostra-se é apropriada, pois garante a esterilização completa do produto.

VITAL, H. C. Experimentos Dosimétricos no Irradiador Gama do IPE. ENCONTRO NACIONAL DE APLICAÇÕES NUCLEARES (ENAN), 5. 2000a, Rio de Janeiro, Anais..., p.15-20.

VITAL, H.C. Mapeamento Dosimétrico do Irradiador Gama do IPE, Nota Técnica Interna do IPE, 2000b.

VITAL, H.C. Notas da Disciplina Ensaios Práticos de Irradiação de Alimentos do Curso de Especialização Lato Sensu em Irradiação de Alimentos da UFF, DDQBN/CTEx, 2005. 